\title{
Attention Deficit Hyperactivity Disorder Prevalence and Correlates Pre- and Post-Bariatric Surgery: A Comparative Cross-Sectional Study
}

\author{
Friedrich Nielsen $^{a} \quad$ Ekaterini Georgiadou ${ }^{a, b}$ Merle Bartsch $^{a}$ \\ Svenja Langenberg ${ }^{a} \quad$ Astrid Müller ${ }^{a}$ Martina de Zwaan ${ }^{a}$ \\ a Department of Psychosomatic Medicine and Psychotherapy, Hanover Medical School, Hanover, \\ Germany; ${ }^{b}$ Department of Psychosomatic Medicine and Psychotherapy, University Hospital \\ Erlangen, University Erlangen-Nuremberg, Erlangen, Germany
}

\section{Key Words}

ADHD · Obesity · Bariatric surgery $\cdot$ Psychopathology $\cdot$ Inattention · CAARS

\begin{abstract}
Objective: Previous research shows an association between obesity and attention deficit hyperactivity disorder (ADHD). The present study compares pre- and post-bariatric surgery patients using the internationally used Conners' Adult ADHD Rating Scale (CAARS'M) to screen for ADHD. Methods: Matched samples pre- $(\mathrm{N}=120)$ and post-bariatric surgery $(\mathrm{N}=128)$ were compared using self-rating instruments to assess ADHD-relevant symptomatology, depression, eating-related psychopathology, and BMI. Results: Prevalence of probable ADHD did not differ between groups using the CAARS Index Scale T-scores; however, CAARS subscales Inattention/Memory and Self-Concept showed significantly lower scores in post-surgery patients. All CAARS subscales correlated significantly with each other, with depression and eating-related psychopathology. There was no correlation between ADHD and excess BMI loss in post-surgery patients. Conclusion: The findings suggest that a considerable number of patients before and after bariatric surgery screened positive for ADHD. It can be hypothesized that some core ADHD symptoms improve after surgery. Future studies are warranted to investigate the influence of ADHD on long-term surgery outcomes.
\end{abstract}

(C) 2017 The Author(s)

Published by S. Karger GmbH, Freiburg

\section{Introduction}

Attention deficit hyperactivity disorder (ADHD) is a childhood-onset, highly heritable neurodevelopmental disorder characterized by impairing inattention, motor hyperactivity, and impulsivity. Around $65 \%$ of patients continue to meet full criteria or have achieved only 
Nielsen et al:: Attention Deficit Hyperactivity Disorder Prevalence and Correlates Preand Post-Bariatric Surgery: A Comparative Cross-Sectional Study

partial remission by adulthood [1]. There are developmental models that suggest that remission of ADHD upon transition into adulthood may be facilitated by the improved cognitive functions of the adult mind. Some studies have indicated that remission over the course of development is associated with improvements in executive control functions [2]. The diagnosis in adulthood requires a positive childhood diagnosis. With regard to the core symptoms, inattentive features are more likely to persist into adulthood than hyperactivity or impulsivity. One meta-analysis on the prevalence of ADHD in adulthood yielded a pooled prevalence of $2.5 \%$ [3]. A Danish registry-based investigation showed substantially increased mortality in adult life in individuals with ADHD compared with individuals without the disorder [4]. ADHD is associated with an adverse impact in health risk indicators well known to be associated with high morbidity and mortality [5].

For the severely obese, bariatric surgery is the only procedure that has been consistently shown to result in long-term weight loss and significant improvement in medical comorbidity [6]. The number of obesity surgery interventions is continuously increasing, also in Germany [7]. As the use of bariatric surgery has become increasingly popular, it has also become obvious that psychiatric problems are common among these patients [8]. Empirical data suggest that many bariatric surgery candidates suffer from mental disorders and decreased cognitive functions that often improve postoperatively [8].

Previous research has shown a clear link between obesity and ADHD. There is ample evidence that ADHD is associated with overweight and obesity in children and adolescents [9]. This association has also been found in adults. ADHD is significantly more frequent in overweight and obese compared to normal-weight adults in the general population, and the prevalence seems to increase with BMI. In obese individuals in a German general population sample, 9.7\% screened positive for ADHD [10]. ADHD is also common in obese treatmentseeking patients and might negatively impact weight loss attempts [11]. Studies estimating the prevalence of ADHD in pre-bariatric surgery patients found frequencies of $7 \%, 8.6 \%$, $10 \%$, and $12.1 \%$ [12-15]. In these pre-bariatric surgery samples, ADHD was associated with greater severity of depressive and anxiety symptoms, disordered eating, more psychotherapy contact in the past, and hazardous alcohol consumption. No differences were found for sex. One study examined the occurrence of ADHD post-bariatric surgery reporting a prevalence rate of 31.6\% [16]. This study did not find an association between ADHD and BMI, depressive symptoms as well as quality of life; however, participants with ADHD had more difficulties with compliance with follow-up visits. The only available longitudinal study examined 129 patients prior and 1 year after bariatric surgery [14]. According to the ADHD self-rating scale [17], 7\% screened positive before and 7.8\% after surgery. Participants who screened positive for ADHD scored significantly higher on the HADS anxiety and depression scales and were more often at risk for an alcohol use disorder as measured with the AUDIT. Moreover, in the same study no significant difference was observed between participants who screened positive or negative for adult ADHD at either occasion with regard to weight loss.

Several studies have shown a link between obesity and cognitive impairment [18] and that bariatric surgery is associated with improvement of cognitive functions [19]. These improvements have been observed in longitudinal studies as early as 12 weeks after surgery [18] and are maintained up to 3 years postoperatively [19]. Cognitive dysfunction related to obesity may thus be at least partially reversible following bariatric surgery.

There is ample evidence that ADHS symptoms can be affected by cognitive control [20]. As mentioned above, longitudinal studies indicated improvement in cognitive function following bariatric surgery [21]. Consequently, it is reasonable to assume that improved cognitive functions after bariatric surgery may contribute to enhanced control of adult ADHD symptoms resulting in a lower prevalence of ADHD in postoperative samples compared to preoperative samples. 
Nielsen et al.: Attention Deficit Hyperactivity Disorder Prevalence and Correlates Preand Post-Bariatric Surgery: A Comparative Cross-Sectional Study

Table 1. Socio-demographic data divided by group

\begin{tabular}{lll}
\hline & $\begin{array}{l}\text { Pre-surgery } \\
(\mathrm{n}=120)\end{array}$ & $\begin{array}{l}\text { Post-surgery } \\
(\mathrm{n}=128)\end{array}$ \\
\hline Age, years & $40.97 \pm 11.46$ & $41.53 \pm 10.67$ \\
BMI before surgery, $\mathrm{kg} / \mathrm{m}^{2}$ & $47.76 \pm 7.41$ & $48.82 \pm 6.43$ \\
Female sex, $\mathrm{n}(\%)$ & $95(79.2 \%)$ & $101(78.9 \%)$ \\
Education $\geq 12$ years, $\mathrm{n}(\%)$ & $26(21.6 \%)$ & $22(17.2 \%)$ \\
\hline
\end{tabular}

To our knowledge, no study to date has compared pre- and post-bariatric surgery patients with respect to ADHD by using the Conners' Adult ADHD Rating Scale (CAARS). This scale for which cross-international validity has been demonstrated [22] is internationally frequently used as a screening instrument of adult ADHD. In addition, the reliability of the four subscales is sufficiently robust that the scales can be used separately for purposes of clinical description and research [23]. Most studies in bariatric surgery patients did not assess ADHD-relevant childhood behaviors in addition to symptoms in adulthood. To fill these gaps and, the aims of our comparative cross-sectional study were to

- investigate the prevalence rates of probable ADHD in a pre- and a post-bariatric surgery sample applying the CAARS to screen for ADHD symptoms in adults and the Wender Utah Rating Scale short version (WURS-k) to assess ADHD-relevant symptoms retrospectively in childhood,

- $\quad$ investigate potential differences in core ADHD symptoms between the pre- and a postsurgery sample, and

- examine correlations between ADHD symptom severity and sex, age, ADHD-relevant childhood behaviors, depression, eating-related psychopathology, effortful control as well as percent total weight loss in the pooled sample and separately in the pre- and the post-bariatric surgery sample.

\section{Material and Methods}

Sample

For the current analyses, the matched pre- and post-surgery samples from 2 separate studies were combined $[24,25]$. The data on ADHD have not been reported before.

The combined sample consisted of 120 pre-bariatric surgery and 128 post-bariatric surgery patients who were matched for age, sex, level of education, and pre-surgery BMI. The mean age of the total sample was 41.3 years (SD 11.0 years, range 19-65 years), the mean pre-surgery BMI was $48.3 \mathrm{~kg} / \mathrm{m}^{2}$ (SD 6.9 $\left.\mathrm{kg} / \mathrm{m}^{2}\right) ; 196(79 \%)$ were women, and $48(19.4 \%)$ reported 12 or more school years. In the post-surgery sample the time since bariatric surgery was 10.5 months (SD 4.7 months, range 2-28 months) and percent total weight loss was 34.8\% (SD 8.8\%, range 11.2-57.9\%). Most patients had received gastric bypass (119, $93 \%)$, and 9 (7\%) had undergone sleeve gastrectomy (table 1).

\section{Assessment}

Conners' Adult ADHD Rating Scale - Self-Report: Short Version (CAARS-S:S).

The CAARS-S:S is a 26-item self-report questionnaire measuring symptoms of ADHD in adults (age 18 years and older). Individuals are asked to rate themselves on a range of symptoms and behaviors associated with ADHD, using a 4-point scale: 0 - 'not at all, never', 1 - 'just a little, once in a while', 2 - 'pretty much, often', 3 - 'very much, very frequently'. It contains the subscales Inattention or Memory Problems (Cronbach's $\alpha=$ 0.773 in our sample), Hyperactivity or Restlessness (Cronbach's $\alpha=0.720$ ), Impulsivity or Emotional Lability (Cronbach's $\alpha=0.796)$, and Problems with Self-Concept (Cronbach's $\alpha=0.893$ ). As with the long version, the ADHD Index (Cronbach's $\alpha=0.843$ ) is incorporated on this form. The German version of the long form (42 items) was validated by Christiansen et al. $[22,23,26]$ and has shown to have good psychometric properties. 
Nielsen et al.: Attention Deficit Hyperactivity Disorder Prevalence and Correlates Preand Post-Bariatric Surgery: A Comparative Cross-Sectional Study

The raw scale scores were transformed into standard $\mathrm{T}$ scores which were derived from the German normative data [27]. T scores of 65 and above indicate clinically significant symptoms.

Wender Utah Rating Scale Short Version (WURS-k).

Participants rated their ADHD symptoms in childhood retrospectively, using the German version of the short version of the Wender Utah Rating Scale (WURS-k) [28] which consists of 21 items to be rated on a 5-point Likert-scale (0-4, 'not at all' to 'severe'). The internal consistency of the WURS-k in our sample was 0.925 (Cronbach's $\alpha$ ). In addition to the 21 items assessing ADHD-specific symptoms in childhood, the WURS-k contains 4 control items assessing symptoms not compatible with the construct. A negative correlation between the score of the ADHD-specific items and the score of the 4 control items is considered to assess the truthfulness and consistency of the answers. The correlation coefficient in our sample was -0.414 ( $p<0.001$ ). As suggested by the authors, we used a cutoff score of $\geq 30$ to indicate the presence of a diagnosis of ADHD in childhood (age 8-10 years). This cutoff has a sensitivity of $85 \%$ and a specificity of $75 \%$ to detect ADHD based on clinical interview.

In addition to the assessment of childhood-only ADHD (WURS-k $\geq 30$ ) and of current ADHD symptoms (ADHD Index T score $\geq 65$ ), we diagnosed participants who fulfilled both the WURS-k and CAARS criteria as probable cases of adult ADHD.

Effortful Control Scale (EC)

Regulative temperament was measured by means of the EC subscale of the Adult Temperament Questionnaire-Short Form (ATQ-EC) [29]. The questionnaire includes 19 items that are rated on a 7-point Likert scale, ranging from 1 ('not at all applicable') to 7 ('completely applicable'), and assess the extent to which high or low levels of effortful control generally characterize the respondents' interaction with the environment (e.g. 'When I am trying to focus my attention, I am easily distracted', 'I hardly ever finish things on time'). The internal consistency of the total scale was sufficiently high in the investigated sample, with a Cronbach's $\alpha$ of 0.734 .

Patient Health Questionnaire-9 (PHQ-9)

Depression was assessed by using the total score of the German version of the 9-item PHQ-9 [30, 31]. The PHQ-9 explores the nine DSM-IV criteria for depression each scoring from 0 ('not at all') to 3 ('nearly every day'), yielding a total score between 0 and 27 . The items refer to problems within the last 2 weeks. A total score $\geq 10$ indicates the presence of a major depressive disorder. The PHQ- 9 has been validated in bariatric surgery patient populations [32]. Cronbach's $\alpha$ in the present study sample was 0.868 .

Eating Disorders Examination - Questionnaire Version (EDE-Q)

The German version of the EDE-Q [33] was used to characterize the sample with regard to specific eating disorder psychopathology. The questionnaire consists of the subscales 'Restraint', 'Eating Concern', 'Weight Concern' and 'Shape Concern'. For the purpose of this study we used the EDE-Q total score. A mean total EDE-Q score $\geq 2.3$ serves as an indicator for the presence of any eating disturbance [34]. Cronbach's $\alpha$ of the mean total score was 0.853 .

Weight and height were taken from the patient charts.

\section{Statistics}

The prevalence rates of ADHD, using different definitions, were calculated as percentages. The pre- and post-surgery samples were compared using t-tests and chi-square tests as appropriate. As effect size estimates Cohen's d was used for t-tests and the phi coefficient was used for chi-square statistics [35]. A d value between 0.1 and 0.3 is a small effect size, between 0.3 and 0.6 a moderate effect size, and bigger than 0.6 a large effect size [36]. For phi, 0.1-0.3 represents a small effect, 0.4-0.5 a medium effect, and more than 0.5 a large effect.

Two-tailed Spearman's rank-order correlations were conducted to determine the relationship of the CAARS T scores with sex, age, childhood symptoms (WURS-k), depression (PHQ), eating-related psychopathology (EDE-Q), effortful control (ATQ-EC), and \%EBMIL were conducted for the total sample and separately for the pre- and the post-bariatric surgery samples. The significance level was set at $\mathrm{p} \leq 0.05$. 
Table 2. Prevalence rates of probable ADHD

Pre-surgery, N Post-surgery, N (\%), Statistics $(\%)(n=120) \quad N(\%)(n=128)$
Effect size, phi

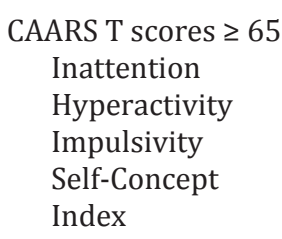

WURS-k total score $\geq 30+$ CAARS-Index T-score $\geq 65$

$28(23.3)$
$15(12.5)$
$26(21.7)$
$38(31.7)$
$23(19.2)$

$19(14.8)$
$14(10.9)$
$20(15.6)$
$20(15.6)$
$20(15.6)$

$10(8.3)$

\section{$\chi^{2} \mathrm{df}=1$ Sign.}

CAARS = Conners' Adult ADHD Rating Scale; WURS-k = Wender Utah Rating Scale, short version (childhood ADHD).

\section{Results}

\section{Prevalence Rates of Probable ADHD Cases}

The prevalence rates of probable ADHD did not differ between groups when using the suggested CAARS Index scale T score cutoff of 65 combined with the WURS-k total score cutoff of 30 (table 2). The rates were $8.3 \%$ in the pre-surgery sample and $6.3 \%$ in the postsurgery sample. Probable ADHD was not associated with sex (male 23.1\%, female 27.6\%), age (40.9 vs. 41.4 years), or educational level.

\section{Psychopathological Differences between Samples}

The pre- and post-bariatric surgery samples differed significantly with regard to depression, eating-related psychopathology, and the T scores of the CAARS subscales Inattention/Memory and Problems with Self-Concept with post-bariatric surgery patients exhibiting significantly lower scores. No differences between samples were found for the WURS-k, the ATQ-EC, the CAARS subscales Hyperactivity, Impulsivity, and the CAARS Index scale (table 3).

\section{Correlational Analyses}

There were significant correlations between all CAARS subscale T scores and the scores for depressive symptoms and eating-related psychopathology (positive) and for effortful control (negative). The CAARS T scores correlated with each other and with the WURS-k total score. No correlations were found with age and sex (table 4). The described correlations between measures did not differ between the pre- and the post-surgery group (data not shown). In the post-bariatric surgery sample no associations were found between percent total weight loss and all CAARS T-scores (Index: $\mathrm{r}=-0.042$; Inattention/Memory: $\mathrm{r}=-0.129$; Hyperactivity: $r=0.099$; Impulsivity: $r=-0.117$; Self-concept: $r=-0.029)$. Percent total weight loss was identical between probable cases of ADHD and non-cases (34.4\% vs. $34.8 \%$ ).

\section{Discussion}

A significant proportion of patients prior and after bariatric surgery screened positive for ADHD. Combining the suggested cutoffs for the WURS-k (= childhood ADHD) and the CAARS (= adult ADHD symptoms) the prevalence rates of probable ADHD were $8.3 \%$ and $6.3 \%$, 
Nielsen et al.: Attention Deficit Hyperactivity Disorder Prevalence and Correlates Preand Post-Bariatric Surgery: A Comparative Cross-Sectional Study

Table 3. Comparison between pre- and post-bariatric surgery samples

\begin{tabular}{|c|c|c|c|c|c|c|}
\hline & \multirow{2}{*}{$\begin{array}{l}\text { Pre-surgery, } \\
\text { mean } \pm \text { SD or } N(\%) \\
(n=120)\end{array}$} & \multirow{2}{*}{$\begin{array}{l}\text { Post-surgery, } \\
\text { mean } \pm \text { SD or } N(\%) \\
(n=128)\end{array}$} & \multicolumn{3}{|c|}{ Statistics } & \multirow{2}{*}{$\begin{array}{l}\text { Effect size, } \\
\text { Cohen's d/phi }\end{array}$} \\
\hline & & & $\mathrm{T} / \chi^{2}$ & $\mathrm{df}$ & Sign & \\
\hline PHQ-9 total score & $8.80 \pm 5.08$ & $4.69 \pm 4.71$ & 6.515 & 238 & $<0.001$ & -0.840 \\
\hline PHQ-9 cutoff $\geq 10$ & $48(42.5 \%)$ & $18(14.2 \%)$ & 24.028 & 1 & $<0.001$ & -0.316 \\
\hline EDE-Q total score & $3.07 \pm 0.87$ & $1.80 \pm 1.16$ & 9.787 & 234.96 & $<0.001$ & -1.233 \\
\hline EDE-Q cutoff $\geq 2.3$ & $94(78.3 \%)$ & $43(33.6 \%)$ & 50.140 & 1 & $<0.001$ & -0.450 \\
\hline WURS-k total score & $17.07 \pm 14.61$ & $15.94 \pm 13.05$ & 0.639 & 238.55 & 0.523 & -0.082 \\
\hline WURS-k total score $>30$ & $21(17.5 \%)$ & $20(15.6 \%)$ & 0.158 & 1 & 0.691 & -0.025 \\
\hline EC total score & $4.39 \pm 0.77$ & $4.55 \pm 0.68$ & -1.653 & 245 & 0.1 & 0.221 \\
\hline \multicolumn{7}{|l|}{ CAARS T-scores } \\
\hline Inattention & $54.17 \pm 12.99$ & $49.42 \pm 11.84$ & 2.999 & 240.03 & 0.003 & -0.383 \\
\hline Hyperactivity & $51.81 \pm 11.19$ & $50.19 \pm 10.89$ & 1.156 & 246 & 0.249 & -0.147 \\
\hline Impulsivity & $55.04 \pm 12.48$ & $53.82 \pm 12.15$ & 0.781 & 246 & 0.436 & -0.099 \\
\hline Self-Concept & $56.15 \pm 14.67$ & $50.09 \pm 14.48$ & 3.419 & 246 & 0.001 & -0.416 \\
\hline ADHD Index & $54.92 \pm 13.03$ & $51.84 \pm 12.83$ & 1.876 & 246 & 0.062 & -0.238 \\
\hline
\end{tabular}

CAARS = Conners' Adult ADHD Rating Scale; EC = Effortful Control subscale of the Adult Temperament Questionnaire; EDE-Q = Eating Disorders Examination, questionnaire version (eating-related psychopathology), PHQ-9=Patient Health Questionnaire-9, Depression Scale; WURS-k = Wender Utah Rating Scale, short version (childhood ADHD).

respectively, which is comparable to obese individuals in a German general population samples [37]. Among the obese individuals in the general population, 9.7\% screened positive for adult ADHD compared to 3.8\% in overweight and 4.3\% in underweight/normal-weight participants.

The results are in line with previous studies in bariatric surgery patients. Although previous studies have used other instruments and have not assessed childhood ADHD, the prevalence rates are, nevertheless, comparable $(7.0 \%, 8.6 \%, 10 \%$, and $12.1 \%)$ [12-15]. The two studies that also screened for ADHD in post-bariatric surgery patients found rates of $7.8 \%$ [14] and 31.6\% [16]. While the latter was a cross-sectional study of 60 subjects with a minimum follow-up of 18 months, Alfonsson et al. [14] conducted a longitudinal study and found comparable rates prior and 12 months after bariatric surgery (7\% vs. 7.8\%). Thus, all bariatric surgery studies except one [16] found rates of probable ADHD cases that resemble those found in obese individuals in general population samples. This is in contrast to the rates found in adult weight loss samples [11,38, 39] which have been reported to range between 27 and 38\%. The lower rates in bariatric surgery patients might be due to a selection process of patients pursuing bariatric surgery [40]. Patients with ADHD may not be organized and persistent enough to adhere to the complex preoperative requirements necessary to obtain approval from the multidisciplinary health care team and the health insurance company [15].

Even though we found no difference in the overall prevalence rates of probable ADHD cases between the pre- and post-surgery sample, some of the core ADHD symptoms were significantly different between samples. The Inattention/Memory as well as the Problems with Self-Concept subscale $\mathrm{T}$ scores were significantly lower in the post-surgery sample. Overall, the effect sizes of these differences between samples were small to medium. In their longitudinal study, Alfonsson et al. [14] also found a significant reduction on the Attention subscale of the ADHD Self-Report Scale [17] for men, but not for women. The finding of a better attention and memory function in the post-surgery sample is in line with the results of longitudinal studies demonstrating improvements in cognitive functioning following bariatric 
Nielsen et al.: Attention Deficit Hyperactivity Disorder Prevalence and Correlates Preand Post-Bariatric Surgery: A Comparative Cross-Sectional Study

Table 4. Two-tailed Spearman's rank-order correlations between CAARS-S:S subscale T-scores, age, sex, WURS-k, effortful control, depression, and eating-related psychopathology for the pooled sample

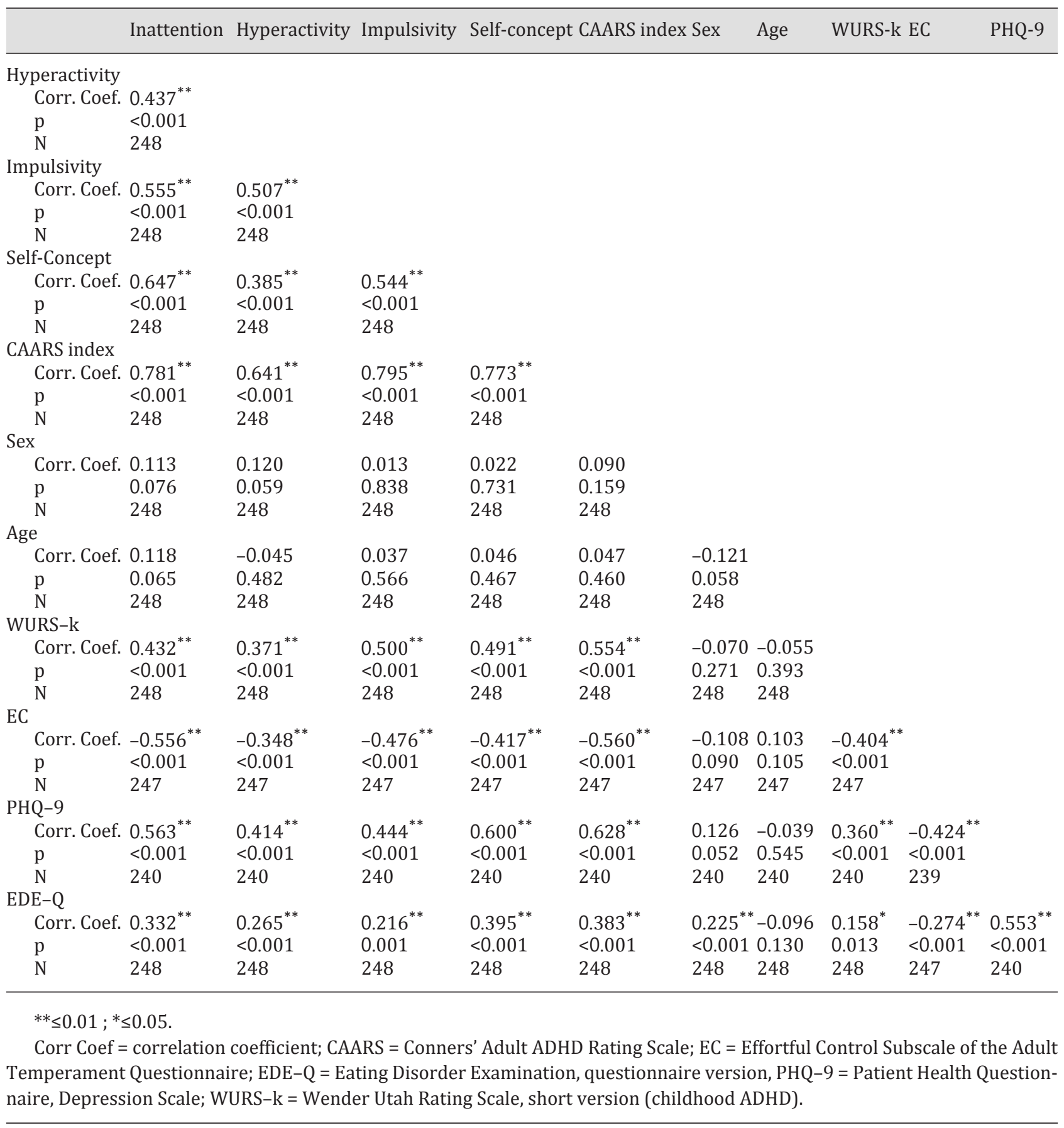

surgery $[18,19,41,42]$. It is reasonable to assume that postoperative cognitive improvement in attention and memory might have impacted the self-report on the respective CAARS subscale, possibly by way of improved prefrontal top-down control. The mechanisms for cognitive dysfunction in severely obese individuals and of improved cognition following bariatric surgery are not well understood and are the topic of ongoing research $[43,44]$. In addition to the potential contribution of medical comorbidities and mental disorders (such 
Nielsen et al.: Attention Deficit Hyperactivity Disorder Prevalence and Correlates Preand Post-Bariatric Surgery: A Comparative Cross-Sectional Study

as depression), it has also been suggested that the greater presence of ADHD may account for some of the cognitive difficulty observed in this population [43].

As expected, scores of depression and eating-related psychopathology were significantly lower in the post-surgery sample with large effect sizes. CAARS subscale T scores were significantly and positively associated with degree of depression and eating-related psychopathology. This is in line with all other studies on this topic and is thought to reflect the high degree of comorbid problems in adults with ADHD [23, 45]. However, an alternative explanation might be that comorbid conditions may produce symptoms which may erroneously be diagnosed as ADHD, since symptoms associated with ADHD are also present in a number of other mental disorders $[15,46]$. The lower degree of comorbid psychopathology in the postsurgery sample might thus explain the significantly lower T scores on the Problems with SelfConcept subscale since there is considerable symptom overlap between scales [14]. With regard to the Self-Concept subscale, it is reasonable to assume that the frequency in which individuals are 'unsure of themselves', 'get down on themselves' and 'lack belief in their abilities' is not only influenced by the challenges adults with ADHD experience in a variety of life domains (such as academic problems, occupational attainment, marital difficulties, and interpersonal problems) but also by the level of depression and other psychopathology. Also in children and adolescents with ADHD, more problems with self-concept were correlated with more internalizing problems [47].

As opposed to inattention and problems with self-concept, other core symptoms of ADHD such as impulsivity and hyperactivity/restlessness did not differ between groups. Whereas some studies found a significant reduction of hyperactivity/impulsivity after bariatric surgery [13], others did not [24, 48]. Ryden et al. [48] examined the 2-year effects of weight change on personality traits in severely obese subjects treated surgically. They used the Karolinska Scales of Personality in 1,135 bariatric surgery patients from the SOS (Swedish Obese Subjects) study. They found that over time differences between the surgically treated and the reference group decreased on all scales except impulsiveness, which remained unchanged. In addition, weight reduction maintained for 2 years was associated with changes on practically all personality traits in proportion to the magnitude of weight loss; only impulsiveness was unaffected. Temperament is expected to show consistency across situations and stability over time [49]. Also effortful control as a component of regulative temperament on average does not differ between pre- and post-surgery samples. Effortful control was indeed not significantly different between the investigated samples; however, not surprisingly it was significantly and negatively related to all CAARS subscales. It is well known that regulation deficits contribute to symptoms of ADHD. This negative association was also found in a latent profile analysis reporting different temperamental subtypes of bariatric surgery candidates [50]. Lack of effortful control could be seen as a core symptom of ADHD [51].

Interestingly, higher ADHD scores were not associated with less weight loss in our postsurgery sample. We have to keep in mind that the mean duration since surgery was only 10 months in our post-surgery sample with a relatively narrow range of 2-28 months. Usually, weight regain is described to occur later on (1-2 years) after a weight plateau has been reached. Once weight loss slows down or stops, psychosocial factors may start to play a more important role in the further course of weight. This is in line with the results of Nicolau et al. [16] and Alfonsson et al. [14]. In both studies there was no correlation between ADHD symptoms and weight loss. As in our study, both studies had a short to medium follow-up of 18 months and 12 months, respectively. Studies focusing on cognitive dysfunction and bariatric surgery could demonstrate that early postoperative cognitive dysfunction predicted reduced weight loss 36 months following surgery [52]. Another study found that weight regain occurring between 24 and 36 months after surgery was associated with a decline in attention [19]. In summary, time since surgery was relatively short, and effects of ADHD and 
Nielsen et al.: Attention Deficit Hyperactivity Disorder Prevalence and Correlates Preand Post-Bariatric Surgery: A Comparative Cross-Sectional Study

specifically of inattention on weight loss might emerge at a later point in time after bariatric surgery, a hypothesis in need of empirical testing.

\section{Strengths}

This is the largest study screening for ADHD in bariatric surgery samples. We used internationally well-known, state of the art self-rating instruments to screen for ADHD in adulthood and also in childhood. The pre- and post-surgery samples were matched.

\section{Limitations}

This study is cross-sectional, using convenience samples which does not allow for longitudinal interpretations. Data were only collected with self-report measurements and formal diagnoses were not assessed in this study.

\section{Conclusion}

It is important to acknowledge that ADHD appears to be a frequent disorder in severely obese patients presenting for bariatric surgery. Also shortly after surgery the prevalence of probable ADHD was significant. Thus, the occurrence of ADHD in bariatric surgery samples is considerable enough to take into account its screening before and after surgery. However, some of the symptoms characteristic for ADHD such as inattention and problems with selfconcept might be lower in post-surgery samples while others are comparable with the presurgery values. Even though the study does not allow longitudinal interpretations, it can be hypothesized that some of the core ADHD symptoms actually might improve after surgery, whereas others remain unchanged. One possible explanation may be stronger top-down control through improved cognitive functions. Even though there was no association between ADHD symptom severity and percent total weight loss in our post-surgery sample, prospective studies using interview-based assessments are warranted to investigate the course of ADHD symptoms in patients undergoing bariatric surgery and to further investigate the potential influence of ADHD symptoms on longer-term post-surgery outcomes.

\section{Disclosure Statement}

The authors do not declare any conflict of interest

\section{References}

1 Thapar A, Cooper M: Attention deficit hyperactivity disorder. Lancet 2016;387:1240-1250.

2 Halperin JM, Trampush JW, Miller CJ, Marks DJ, Newcorn JH: Neuropsychological outcome in adolescents/ young adults with childhood ADHD: profiles of persisters, remitters and controls. J Child Psychol Psychiatry 2008;49:958-966.

3 Simon V, Czobor P, Bálint S, Mészáros A, Bitter I: Prevalence and correlates of adult attention-deficit hyperactivity disorder: meta-analysis. Br J Psychiatry 2009;194:204-211.

4 Dalsgaard S, Østergaard SD, Leckman JF, Mortensen PB, Pedersen MG: Mortality in children, adolescents, and adults with attention deficit hyperactivity disorder: a nationwide cohort study. Lancet 2015;385:2190-2196.

5 Spencer TJ, Faraone SV, Tarko L, McDermott K, Biederman J: Attention-deficit/hyperactivity disorder and adverse health outcomes in adults. J Nerv Ment Dis 2014;202:725-731.

6 Sjöström L: Review of the key results from the Swedish Obese Subjects (SOS) trial - a prospective controlled intervention study of bariatric surgery. J Intern Med 2013;273:219-234.

7 Stroh C, Weiner R, Wolff S, Knoll C, de Zwaan M, Manger T: Comment on gender-specific aspects in obesity and metabolic surgery - analysis of data from the German Bariatric Surgery Registry. Zentralbl Chir 2015;140: 285-293. 
Nielsen et al:: Attention Deficit Hyperactivity Disorder Prevalence and Correlates Preand Post-Bariatric Surgery: A Comparative Cross-Sectional Study

8 Müller A, Mitchell JE, Sondag C, de Zwaan M: Psychiatric aspects of bariatric surgery. Curr Psychiatry Rep 2013;15:397.

9 Racicka E, Hanć T, Giertuga K, Bryńska A, Wolańczyk T: Prevalence of overweight and obesity in children and adolescents with ADHD: the significance of comorbidities and pharmacotherapy. J Atten Disord 2015; DOI: $10.1177 / 1087054715578272$.

10 de Zwaan M, Gruss B, Müller A, Philipsen A, Graap H, Martin A, Glaesmer H, Hilbert A: Association between obesity and adult attention-deficit/hyperactivity disorder in a German community-based sample. Obes Facts 2011;4:204-211.

11 Levy LD, Fleming JP, Klar D: Treatment of refractory obesity in severely obese adults following management of newly diagnosed attention deficit hyperactivity disorder. Int J Obes (Lond) $2009 ; 33: 326-334$

12 Alfonsson S, Parling T, Ghaderi A: Screening of adult ADHD among patients presenting for bariatric surgery. Obes Surg 2012;22:918-926.

13 Alfonsson S, Parling T, Ghaderi A: Self-reported symptoms of adult attention deficit hyperactivity disorder among obese patients seeking bariatric surgery and its relation to alcohol consumption, disordered eating and gender. Clin Obes 2013;3:124-131.

14 Alfonsson S, Sundbom M, Ghaderi A: Is age a better predictor of weight loss one year after gastric bypass than symptoms of disordered eating, depression, adult ADHD and alcohol consumption? Eat Behav 2014;15:644647.

15 Gruss B, Mueller A, Horbach T, Martin A, de Zwaan M: Attention-deficit/hyperactivity disorder in a prebariatric surgery sample. Eur Eat Disord Rev 2012;20:e103-107.

16 Nicolau J, Ayala L, Francés C, Sanchís P, Zubillaga I, Pascual S, Fortuny R, Masmiquel L: Are subjects with criteria for adult attention-deficit/ hyperactivity disorder doing worse after bariatric surgery? A case-control study. Nutr Hosp 2014;31:1052-1058.

17 Kessler RC, Adler L, Ames M, Demler O, Faraone S, Hiripi E, Howes MJ, Jin R, Secnik K, Spencer T, Ustun TB, Walters EE: The World Health Organization Adult ADHD Self-Report Scale (ASRS): a short screening scale for use in the general population. Psychol Med 2005;35:245-256.

18 Gunstad J, Strain G, Devlin MJ, Wing R, Cohen RA, Paul RH, Crosby RD, Mitchell JE: Improved memory function 12 weeks after bariatric surgery. Surg Obes Relat Dis 2011;7:465-472.

19 Alosco ML, Galioto R, Spitznagel MB, Strain G, Devlin M, Cohen R, Crosby RD, Mitchell JE, Gunstad J: Cognitive function after bariatric surgery: evidence for improvement 3 years after surgery. Am J Surg 2014;207:870876.

20 Safren SA, Otto MW, Sprich S, Winett CL, Wilens TE, Biedermann J: Cognitive-behavioral therapy for ADHD in medication-treated adults with continued symptoms. Behav Res Ther 2005;43:831-842.

21 Spitznagel MB, Hawkins M, Alosco M, Galioto R, Garcia S, Miller L, Gunstad J: Neurocognitive effects of obesity and bariatric surgery. Eur Eat Disord Rev 2015;23:488-495.

22 Christiansen H, Kis B, Hirsch O, Philipsen A, Henneck M, Panczuk A, Pietrowsky R, Hebebrand J, Schimmelmann BG: German validation of the Conners Adult ADHD Rating Scales-self-report (CAARS-S) I: factor structure and normative data. Eur Psychiatry 2011;26:100-107.

23 Christiansen H, Kis B, Hirsch O, Matthies S, Hebebrand J, Uekermann J, Abdel-Hamid M, Kraemer M, Wiltfang J, Graf E, Colla M, Sobanski E, Alm B, Rösler M, Jacob C, Jans T, Huss M, Schimmelmann BG, Philipsen A: German validation of the Conners Adult ADHD Rating Scales (CAARS) II: reliability, validity, diagnostic sensitivity and specificity. Eur Psychiatry. 2012;27:321-328.

24 Georgiadou E, Gruner-Labitzke K, Köhler H, de Zwaan M, Müller A: Cognitive function and nonfood-related impulsivity in post-bariatric surgery patients. Front Psychol 201419;5:1502.

25 Langenberg S, Schulze M, Bartsch M, Gruner-Labitzke K, Pek C, Köhler H, Crosby RD, Marschollek M, de Zwaan M, Müller A: Physical activity is unrelated to cognitive performance in pre-bariatric surgery patients. J Psychosom Res 2015;79:165-170.

26 Christiansen H, Hirsch O, Philipsen A, Oades RD, Matthies S, Hebebrand J, Ueckermann J, Abdel-Hamid M, Kraemer M, Wiltfang J, Graf E, Colla M, Sobanski E, Alm B, Rösler M, Jacob C, Jans T, Huss M, Schimmelmann BG, Kis B: German validation of the Conners adult ADHD rating scale-self-report: confirmation of factor structure in a large sample of participants with ADHD. J Atten Disord 2013;17:690-698.

27 Christiansen H, Hirsch O, Abdel-Hamid M, Kis B: Conners Skalen zur Aufmerksamkeit und Verhalten für Erwachsene (CAARS ${ }^{\mathrm{TM}}$ ). Deutschsprachige Adaptation der Conners' Adult ADHD Rating Scales (CARRS ${ }^{\mathrm{TM}}$ ) von C. Keith Conners, Drew Erhardt und Elizabeth Sparrow. Bern, Hans Huber, 2014.

28 Rösler M, Retz W, Retz-Junginger P, Thome J, Supprian T, Nissen T, Stieglitz RD, Blocher D, Hengesch G, Trott GE: Reliability and validity of the German short version of the Wender-Utah Rating Scale for the retrospective assessment of attention deficit/hyperactivity disorder (in German). Nervenarzt 2003;74:987-993.

29 Wiltink J, Vogelsang U, Beutel ME: Temperament and personality: the German version of the Adult Temperament Questionnaire (ATQ). Psychosoc Med 2006;3:Doc10.

30 Löwe B, Kroenke K, Herzog W, Gräfe K: Measuring depression outcome with a brief self-report instrument: sensitivity to change of the Patient Health Questionnaire (PHQ-9). J Affect Disord 2004;81:61-66.

31 Spitzer RL, Kroenke K, Williams JB: Validation and utility of a self-report version of PRIME-MD: The PHQ primary care study: Primary Care Evaluation of Mental Disorders. Patient Health Questionnaire. JAMA 1999; 282:1737-1744. 
Nielsen et al.: Attention Deficit Hyperactivity Disorder Prevalence and Correlates Preand Post-Bariatric Surgery: A Comparative Cross-Sectional Study

32 Cassin S, Sockalingam S, Hawa R, Wnuk S, Royal S, Taube-Schiff M, Okrainec A: Psychometric properties of the Patient Health Questionnaire (PHQ-9) as a depression screening tool for bariatric surgery candidates. Psychosomatics 2013;54:352-358.

33 Hilbert A, Tuschen-Caffier B: Eating Disorder Examination-Questionnaire. Deutschsprachige Übersetzung. Münster, Verlag für Psychotherapie, 2006.

34 Hilbert A, de Zwaan M, Braehler E: How frequent are eating disturbances in the population? Norms of the eating disorder examination-questionnaire. PLoS One 2012; 7:e29125.

35 Fritz CO, Morris PE, Richler JJ. Effect size estimates: current use, calculations, and interpretation. J Exp Psychol Gen 2012;141:2-18.

36 Cohen J: Statistical Power Analysis for the Behavioral Sciences. London, Routledge, 1977.

37 de Zwaan M, Gruss B, Müller A, Graap H, Martin A, Glaesmer H, Hilbert A, Philipsen A: The estimated prevalence and correlates of adult ADHD in a German community sample. Eur Arch Psychiatry Clin Neurosci 2012;262: 79-86.

38 Altfas JR: Prevalence of attention deficit/hyperactivity disorder among adults in obesity treatment. BMC Psychiatry 2002;2:9.

39 Fleming JP, Levy LD, Levitan RD: Symptoms of attention deficit hyperactivity disorder in severely obese women. Eat Weight Disord 2005;10:e10-13.

40 Rutledge T, Adler S, Friedman R: A prospective assessment of psychosocial factors among bariatric versus non-bariatric surgery candidates. Obes Surg 2011;21:1570-1579.

41 Miller LA, Crosby RD, Galioto R, Strain G, Devlin MJ, Wing R, Cohen RA, Paul RH, Mitchell JE, Gunstad J: Bariatric surgery patients exhibit improved memory function 12 months postoperatively. Obes Surg 2013;23:15271535.

42 Lavender JM, Alosco ML, Spitznagel MB, Strain G, Devlin M, Cohen R, Paul R, Crosby RD, Mitchell JE, Wonderlich SA, Gunstad J: Association between binge eating disorder and changes in cognitive functioning following bariatric surgery. J Psychiatr Res 2014;59:148-154.

43 Galioto R, Gunstad J, Heinberg LJ, Spitznagel MB: Adherence and weight loss outcomes in bariatric surgery: does cognitive function play a role? Obes Surg 2013;23:1703-1710.

44 Spitznagel MB, Gunstad J, Manderino L, Heinberg L: Liver fibrosis predicts cognitive function following bariatric surgery: a preliminary investigation. Obesity (Silver Spring) 2015;23:1957-1959.

45 Nazar BP, Pinna CM, Coutinho G, Segenreich D, Duchesne M, Appolinario JC, Mattos P: Review of the literature of attention-deficit/hyperactivity disorder with comorbid eating disorders. Rev Bras Psiquiatr 2008;30:384389.

46 Harrison AG, Nay S, Armstrong IT: Diagnostic accuracy of the Conners' Adult ADHD Rating Scale in a postsecondary population. J Atten Disord 2016; DOI: 10.1177/1087054715625299.

47 Houck G, Kendall J, Miller A, Morrell P, Wiebe G: Self-concept in children and adolescents with attention deficit hyperactivity disorder. J Pediatr Nurs 2011;26:239-247.

48 Rydén A, Sullivan M, Torgerson JS, Karlsson J, Lindroos AK, Taft C: A comparative controlled study of personality in severe obesity: a 2-y follow-up after intervention. Int J Obes Relat Metab Disord 2004;28:1485-1493.

49 Rothbart MK, Ellis LK, Posner MI: Temperament and self-regulation; in Vohs KD, Baumeister RF (eds): Handbook of Self-Regulation: Research, Theory, and Applications. New York, Guilford Press, 2004, pp 441-460.

50 Müller A, Claes L, Wilderjans TF, de Zwaan M: Temperament subtypes in treatment seeking obese individuals: a latent profile analysis. Eur Eat Disord Rev 2014;22:260-266.

51 Martel MM, Nigg JT: Child ADHD and personality/temperament traits of reactive and effortful control, resiliency, and emotionality. J Child Psychol Psychiatry 2006;47:1175-1183.

52 Spitznagel MB, Alosco M, Galioto R, Strain G, Devlin M, Sysko R, Crosby RD, Mitchell JE, Gunstad J: The role of cognitive function in postoperative weight loss outcomes: 36-month follow-up. Obes Surg 2014;24:10781084 . 